\title{
An enhanced particle swarm optimization algorithm for improving the renewable energy penetration and small signal stability in power system
}

\author{
T. K. Renuka ${ }^{1,2^{*}}\left(0\right.$, P. Reji $^{3}$ and Sasidharan Sreedharan ${ }^{4}$
}

\begin{abstract}
In power systems, increasing the renewable energy penetration with small signal stability is one of the demanding and critical tasks in recent days. This research work aims to develop a multistage optimization technique, namely particle swarm optimization (PSO), for improving both the energy penetration and small signal stability. Here, the wind and solar power sources are considered, and its penetration is maximized by satisfying the grid requirements such as the bus voltage, line flows, and real and reactive power generation within the limit. This work includes two stages: in the first stage, PSO algorithm is implemented for maximizing the renewable energy penetration to the test systems. Then, in the second stage, the small signal stability of the systems is improved with maximum renewable energy penetration in which the best locations for connecting the wind farm are identified by using the calculation of wind farm placement index and solar generation is fixed by considering voltage and bus load absorption capability. During simulation, the proposed method is tested and validated by using IEEE 14-bus standard system, and the $220 \mathrm{kV}$ Kerala (India) grid practical system with the solar and wind power. Moreover, various measures such as power generation, load and bus voltage are evaluated for two different case studies. In this evaluation, it is proved that the renewable energy sources are safely integrated with the power system with increased energy penetration and improved small signal stability.
\end{abstract}

Keywords: Renewable energy source (RES), Energy penetration, Damping ratio reduction, Particle swarm optimization (PSO), Eigenvalue computation, Wind and solar resource

\section{Introduction}

Renewable energy source (RES) such as wind and solar power has an increased impact on the stability of power system, in which the electromechanical oscillations can be occurred due to the small changes in the operating parameters (Kroposky et al. 2017). Normally, energy is an important consideration in all countries, which improves the social, economic development and eminence of mankind's life (Eitigani and Masri 2015). The energy consumption has been increased in recent days, which lead

\footnotetext{
*Correspondence: renuka_mhn@yahoo.co.in

${ }^{1}$ Department of Electrical and Electronics Engg., Govt. Engg. College,

Thrissur, Kerala, India

Full list of author information is available at the end of the article
}

to the rapid depletion of the conventional energy sources (Mehta et al. 2014). So, it is highly important to identify an efficient way for utilizing the energy resources. Renewable energy (Wei et al. 2017) is an important source for generating the electricity, which has the major benefits of reduced operating cost, minimized dependence of fossil fuels and increased reliability of electric power systems. The photovoltaic, marine, solar, wind, hydropower, geothermal and biomass are some kinds of renewable energy sources. When compared to the other resources, wind and solar are the major resources, in which wind energy is generated from the wind power by using the wind turbines. The wind power requires the kinetic energy of the moving air that converts the mechanical energy into the electrical energy (Sandhu and Thakur 2014). Generating 
a greener power generation reduces the emission of carbon dioxide with increased renewable energy generation (Liu et al. 2017). The price of electricity generation, energy payback time and greenhouse gas emission are the primary indicators of energy sustainability. The main intentions (Krismanto et al. 2015) of developing an offshore wind energy are to build large power plants, to locate high-quality wind resources at sea and to reduce the land-based transmission infrastructure. Moreover, the solar energy uses the sun's energy to provide hot water via solar thermal systems through solar photovoltaic (PV) and concentrating solar power (CSP) systems (Bessa et al. 2014). So, it is highly important to penetrate (Nikolic et al. 2015) the renewable energy sources for satisfying the demand of electricity (Edrah et al. 2015). In the traditional works (Khare et al. 2016), various optimization techniques are developed to optimize the parameters for reducing the damping ratio. But, it has the major limitations of increased computational complexity, cost consumption and reduced efficiency (Liu et al. 2015). Thus, this paper aims to develop a multistage optimization technique for improving both the renewable energy penetration and small signal stability. The major objectives of this paper are as follows:

- To improve the renewable energy penetration, a particle swarm optimization (PSO) technique is implemented.

- To analyze the small signal stability of the system, the eigenvalues and damping ratios are calculated.

- To increase the damping ratios and hence to improve small signal stability of the system with maximum renewable energy penetration, PSO-based optimization is implemented.

The rest of the sections in the paper are organized as follows: The "Methods" section surveys existing designs and methodologies that are used to renewable energy penetration and damping ratio improvement, presents the clear description about the proposed PSO based renewable energy penetration and small signal stability maintenance system and explains two case studies. The simulation results are evaluated with respect to different case studies in "Results and discussions" section.

\section{Methods}

\section{Related works}

In this section, the existing techniques and frameworks related to renewable energy penetration and damping ratio reduction are presented.

Edrah et al. (2015) investigated the impact of DFIG based on its rotor angle stability for the integration of wind power with the power systems. In this design, the rotor-side converter (RSC) and grid-side converter (GSC) were utilized to provide the reactive power support to the grid during the fault occurrence. Here, a Western System Coordinating Council (WSCC) was utilized to validate the suggested approach under small and large disturbances. Mehta et al. (2015) designed a controller using particle swarm optimization (PSO) algorithm for developing the DFIGbased wind power system. The intention of this paper was to reduce the oscillations in both electromagnetic torque and rotor currents. Here, the oscillation modes of DFIG were analyzed under varying operating conditions such as grid strength and wind speed. In this design, the reason of using MPPT was to extract the maximum power from the wind. Moreover, the torque control scheme was utilized to modify the electromagnetic torque of the generator based on the speed of wind. Also, the voltage control scheme satisfied the requirements of reactive power compensation and too high or too low terminal voltage. Sreedharan et al. (2015) utilized a PSO algorithm for adjusting the grid control settings by maximizing the renewable penetration of all layers in grid. The main focus of this paper was to maintain both line and voltage stability by stabilizing the grid. Here, the optimal loading pattern was identified to determine the instantaneous penetration based on the fitness function. Also, the bus used for connecting the wind farm index was identified by calculating the placement index. Chatterjee et al. (2016) designed a teaching learning-based optimization (TLBO) technique for analyzing the signal stability of DFIG wind power system. Here, the dynamic performance of the DFIG system was controlled by the use of proportional-integral (PI) controllers. The main contribution of this paper was to reduce the damping phenomena oscillation by analyzing the rotor currents and fluctuations in the electromagnetic torque.

Tang et al. (2015) implemented a new controller design by using a goal representation heuristic dynamic programming (GrHDP) for increasing the system transient stability under different fault conditions. Here, the interaction between the controller and power plant was analyzed by using an adaptive dynamic programming (ADP) technique. The control mechanisms that are used in this work were power optimization and limitation mechanism, which were responsible for controlling the active and reactive power of the DFIG. The suggested GrHDP based contains three modules such as action network, critic network and reference network. However, this paper required to improve the stability of the large-scale interconnected power system. Byrne et al. (2016) quantified the impact of wind and photovoltaic generation on the inter-area modes of American power system. Here, an optimal control scheme was utilized to mitigate the modes and the communication delay of the control system. The main focus of this paper was to improve the 
stability for the lower frequency NS-A mode. Krishan et al. (2014) investigated the penetration of distributed solar PV- and DFIG-based wind generation in power systems. Here, different modes such as local mode, interarea mode and critical mode of the system were allocated by using the grid-connected distributed PV generation. In this design, the solar photovoltaic generator (SPVG) system was connected with grid, which contains the solar panels, DC/DC and DC/AC converters.

Erdinc et al. (2015) provided an overview about the insulator power system structures and operational requirements under an increased penetration of renewable energy source. In this paper, an overview about the insular power system structure was provided. Here, the frequency and voltage stability measures were improved by reducing the inertia in an isolated power system. Sahu et al. (2014) developed a power system stabilizer (PSS) by using PSO technique for increasing the damping and steady-state stability margin. The main focus of this paper was to maintain the system stability by optimally tuning the parameters of PSO. The measures such as settling time, speed and overshoot of the machines were reduced under varying disturbances. Pandey et al. (2014) introduced a robust controller for regulating the frequency of the hybrid power system by using the PSO algorithm. In this design, two types of configurations were considered such as hybrid configuration and two-area interconnected power system, in which the thermal power system (TPS) was integrated with DG during the hybrid configuration. Moreover, the linear matrix inequalities (LMI) and its parameters were considered in the suggested control scheme. The robustness of the controller was validated under varying load disturbances, wind power and parameter variations.

Ray et al. (2016) designed a robust power system stabilizer (PSS) by using a swarm and bacterial foraging-based optimization techniques for maintaining the stability of the power system. In this design, a single machine infinite bus (SMIB) was considered to analyze the stability of the system. The major intention of using the optimization techniques was to optimize the parameters that are used for the controller design. Here, the settling time and peak overshoot measures were considered to analyze the frequency oscillations of the system. Rahman et al. (2015) analyzed the operation and controlling strategies of integrated distributed energy sources for reducing the emissions and resistive losses. Here, five distributed energy resources and its controlling strategies were investigated for modernized power systems. Liu et al. (2014) studied the impact of large-scale wind power integration on small signal stability. Based on wind farm integration coupled with a single-machine infinite-bus system, it was observed that, compared with the synchronous generator, a wind farm greatly reduces the small signal stability region boundary and the small signal stability of the power system. Yan and Sekar (2002) studied the effectiveness of the linear models of power systems and observed that linear models are delivering results that are close to the full nonlinear models. Here the linear model results were compared with the correct results after complete convergence is obtained for the IEEE 14-bus system.

From the survey, it is observed that the traditional techniques have both benefits and demerits. But, it mainly lacks with the limitations of reduced efficiency, increased complexity and cost. To solve these issues, this paper aims to develop a multi-level optimization by adjusting the grid parameters assuring grid stability.

\section{Proposed method}

In this section, the clear description about the proposed scheme is presented with its flow representation. The main objectives of this work are to improve the renewable energy penetration meeting all the grid requirements and to improve the small signal stability of the grid at maximum renewable penetration by a quite unique approach and methodology.

This methodology comprises two stages, in which the particle swarm optimization (PSO) algorithm is implemented in the first stage for maximizing the penetration of the renewable resources such as wind and solar by keeping all parameters based on the grid requirements. Then, the small signal stability of the system is optimized in the second stage with maximum renewable energy penetration in which the best location is identified by using WFPI for connecting the wind farm (Sreedharan et al. 2010), and the solar generation is fixed by considering the limiting values of voltage and bus load absorption capability. These two stages are applied on an IEEE 14-bus system and Kerala grid with solar and wind power. The flow of the proposed system is depicted in Fig. 1.

In this design, the multi-objective problem is considered for maximizing the renewable energy penetration and optimizing the damping ratios by fulfilling the stability constraints based on the following equation:

$$
\text { Maximize } J(x, u)=\left\{J_{1}(x, u)+J_{2}(x, u)\right\}
$$

where $J_{1}$ and $J_{2}$ indicate two objective functions, which represents the renewable energy penetration and damping ratio optimization, $x$ represents the vector of dependent variables and $u$ is the vector of control variables.

\section{Renewable energy penetration}

The main aim of optimization is to increase the share of renewable energy in the grid, which is illustrated as follows: 


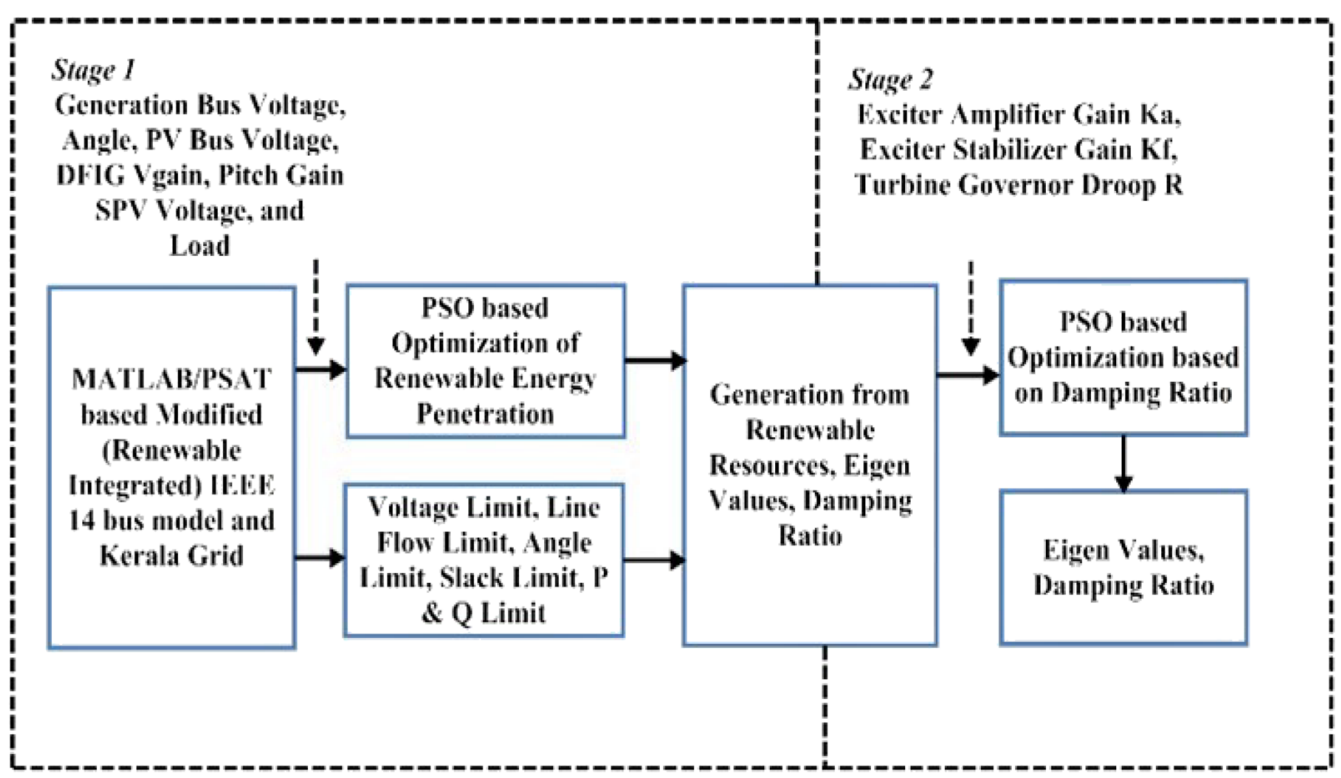

Fig. 1 Flow of the proposed system

Maximize $\quad J_{1}(x, u)=\left\{\exp \gamma\left|\lambda_{\mathrm{f}}-\lambda_{\mathrm{f}}^{\max }\right| \lambda_{\mathrm{f}} \in 1, \lambda_{\mathrm{f}}^{\max }\right\}$

Subjected to

$$
\begin{aligned}
& \mathrm{VL}=\sum_{i=1}^{\mathrm{Nl}} \mathrm{OLL}_{i} * \sum_{j=1}^{\mathrm{Nb}} \mathrm{BVV}_{j} \\
& \left.\begin{array}{l}
\text { if } \quad P_{i j} \leq P_{i j}^{\max } \\
\text { Otherwise }
\end{array}\right\} \\
& \left.\mathrm{OLL}_{i}=\left\{\operatorname{lexp}^{1} \tau_{\mathrm{OLL}}\left|1-\frac{P_{i j}}{P_{i j}^{\max }}\right|\right]\right\} \\
& \mathrm{BVV}_{j}=\left\{\begin{array}{ll}
1 & \text { if } 0.95 \leq V_{b} \leq 1.05 \\
\left\{\exp \left[\tau_{\mathrm{BVV}}\left|1-V_{b}\right|\right]\right\} & \text { Otherwise }
\end{array}\right\}
\end{aligned}
$$

where $\lambda_{\mathrm{f}}=$ load factor $=1$ as base case, $\gamma=$ coefficient to adjust the slope of the function $\lambda_{\mathrm{f}}^{\max }=\max$. limit of load factor. VL defines the thermal and bus violation limit factor, $\mathrm{OLL}_{i}$ is the overload line factor of line $i, \mathrm{BVV}_{j}$ indicates the bus voltage violation factor at bus $j, \mathrm{Nl}$ and $\mathrm{Nb}$ are the total number of transmission lines and total number of buses in the system, respectively, and $\tau_{\mathrm{BVV}}$ and $\tau_{\mathrm{OLL}}$ are the coefficients that used to adjust the slope of functions. The load factor $\lambda_{\mathrm{f}}$ reflects the variation of power loads $P_{D i}$ and $Q_{D j}$, which are defined as follows:

$$
P_{D i}\left(\lambda_{f}\right)=\lambda_{f} P_{D i}: Q_{D i}\left(\lambda_{f}\right)=\lambda_{\mathrm{f}} Q_{D}
$$

\section{Damping ratio optimization}

The damping ratio $\zeta=\frac{-\sigma}{\sqrt{\sigma^{2}+\omega^{2}}}$ represents the decay of amplitude of oscillations, and a negative real part of a complex pair eigenvalues, i.e., $\lambda=\sigma \pm j \omega$ indicates that the oscillations are damped. To optimize the damping ratio, $\mathrm{J} 2$ is maximized as follows:

$$
\operatorname{Max} J_{2}(x, u)=\sum_{i=1}^{n} \zeta_{i}
$$

The dependent variables in the optimization are the exciter amplifier gain $K_{\mathrm{a}}$, exciter stabilizer gain $K_{f}$ and turbine governor droop $R$.

The power flow problem is formulated by obtaining the solution of a nonlinear set of equations, which is shown in below:

$$
\dot{x}=0=f(x, y) \quad \text { and } \quad 0=g(x, y)
$$

where $y$ is defined as the vector of algebraic variables (i.e., voltage amplitude $(\mathrm{V})$ and phases $(\theta))$.

\section{Equality constraints}

Here, the equality constraints are used in the optimization problem, in which the total real and reactive power generations $P_{G i}$ and $Q_{G i}$ are estimated. Then, each generator maintains the load generation profile as shown in below: 


$$
\begin{aligned}
& P_{G i}=P_{L i}+V_{i} \sum_{j=1}^{N} V_{j}\left(G_{i j} \cos \delta_{i j}+B_{i j} \sin \delta_{i j}\right) \\
& Q=Q_{L i}+V_{i} \sum_{j=1}^{N} V_{j}\left(G_{i j} \sin \delta_{i j}+B_{i j} \cos \delta_{i j}\right)
\end{aligned}
$$

where $i=1,2 \ldots N$;

\section{Inequality constraints}

In this system, the parameters such as apparent power flow limit, bus voltage limit, slack generator power output limit and wind power output limit are considered as the inequality constraints.

Apparent power flow limit- $S_{i j} \leq S_{i j \max }$

Bus voltage limit- $V_{i \min } \leq V_{i} \leq V_{i \max }$

Slack generator power output limit-

$P_{\text {slack }} \leq P_{\text {slackmax }}$

$Q_{\text {slack }} \leq Q_{\text {slackmax }}$

$\begin{aligned} P_{\text {wind }} & \leq P_{\text {windmax }} \\ Q_{\text {wind }} & \leq Q_{\text {windmax }} .\end{aligned}$

The dependent variables used in this analysis are the power of generator buses, voltage of load buses, reactive power output of generators and apparent power flow. The control variables that considered in this design are the voltages of PV bus, generation bus voltage, angle, loads, voltage of SPV, voltage gain and pitch gain of DFIG.

\section{Fast voltage stability indices (FVSI)}

The FVSI assures that no bus can get collapsed due to the problem of overloading. Taking the symbols ' $i$ ' as the sending bus and ' $j$ ' as the receiving bus, the fast voltage stability index FVSI can be defined as follows:

$$
\mathrm{FVSI}=\frac{4 Z^{2} Q_{j}}{V_{i}^{2} X}
$$

where $Z$ indicates the line impedance, $X$ is the line reactance, $Q_{j}$ is the reactive power at the receiving end bus and $V_{i}$ denotes the sending end bus voltage.

\section{Line stability index}

The line stability index $L_{m n}$ is calculated based on a power transmission concept in a single line. Taking the symbols ' $s$ ' as the sending and ' $r$ ' as the receiving end of the line, $L_{m n}$ is defined as follows:

$$
L_{m n}=\frac{4 Q_{\mathrm{r}} X}{\left[\left|V_{\mathrm{s}}\right| \sin (\theta-\delta)^{2}\right]}
$$

where $X$ is the line reactance, $Q_{\mathrm{r}}$ defines the reactive power at the receiving end of transmission line, $V_{\mathrm{s}}$ denotes the sending end voltage, $\theta$ is the line impedance angle, and $\delta$ is the angle difference between the supply voltage and receiving voltage. The value of $L_{m n}$ must be less than the value of 1 for maintaining the system stability.

\section{Line stability factor}

The line stability factor (LQP), based on a power transmission concept in a single line, assures the system stability, which is expressed as follows:

$$
\mathrm{LQP}=4\left(\frac{X}{V_{i}^{2}}\right)\left(\frac{X}{V_{i}^{2}} P_{i}^{2}+Q_{j}\right)
$$

where $X$ is the line reactance, $V_{i}$ is the voltage at the sending end bus, $P_{i}$ is the active power at the sending end bus and $Q_{j}$ is the reactive power at the receiving end bus. To maintain a secure condition, LQP should be maintained below 1 .

\section{Wind farm placement index}

The bus at which the wind farm to be placed was identified by the calculation of wind farm placement index (WFPI) by taking into account the parameters such as voltage limits and voltage stability, wind speed, interconnecting cable length and bus load absorption capability (Sreedharan et al. 2010). Interconnection bus should not be weak (higher the voltage stronger the bus), and tangent vector of node voltage determines the relative weakness of the bus. A bus bar within the major power system grid is stronger than bus in a separate small mesh of load busses connecting to a single node of the major grid. The wind farm placement index is given by

$$
I_{w p j}=R_{w j}+C_{\mathrm{v}} R_{\mathrm{v} j}+\left(1 / C_{\mathrm{VSI}}\right) R_{\mathrm{VSI} j}+\left(\frac{1}{C_{\mathrm{l}}}\right) R_{i j}+I_{\text {grid } j}
$$

where $R_{w j}$ is the wind speed rank of bus $j, C_{\mathrm{v}}$ is the voltage constant, $R_{\mathrm{v} j}$ is the voltage rank of bus $j, C_{\mathrm{VSI}}$ is the voltage sensitivity index constant, $R_{\mathrm{VSI}}$ is the voltage sensitivity index rank of bus $j, C_{1}$ is the interconnection cable 
length constant, $R_{i j}$ is the interconnection cable length rank of bus $j$ and $I_{\text {gridj } j}$ is the index of grid connection of bus $j$.

$R_{w j}=1$; if $6 \leq w j \leq 9 ; R_{w j}=2$ if $w j \leq 6 ; R_{w j}=3$ if $w j \geq 9$. $R_{v j}=0$; if $j=$ generator bus or having SVC.

Else rank bus bars from higher voltage level to lower. To obtain $R_{\mathrm{VSI}}$, find 1 /abs (VSI); rank bus bars from higher value to lower.

(The highest sensitivity index results in the weakest bus and vice versa).

To obtain $R_{i j}$, find $1 /$ (cable length); rank bus bars from higher value to lower.

$I_{\text {grid } j}=0$; for major power system grid else $I_{\text {grid } j}==$ number of buses in the small mesh of load buses getting connected to the single node of the major grid.

$C_{\mathrm{v}}=1.5$

$C_{\mathrm{VSI}}=0.375 \times$ number of buses considered suitable for wind farm placement.

In stage 2 , the damping ratio with maximum renewable penetration is maximized by keeping all parameters in a safe limit. The control variables that are used in the optimization of damping ratios are the exciter amplifier gain $K_{\mathrm{a}}$, exciter stabilizer gain $K_{f}$ and turbine governor droop $R$. Here, the Newton-Raphson model is mainly used to calculate the eigenvalues and damping ratio.

\section{Particle swarm optimization}

PSO is one of the widely used optimization techniques that works, based on swam intelligence, in which the search is performed based on the speed of particle. The major reasons of using PSO are: it does not require any overlapping and mutation calculation, simple calculation and very fast searching speed. The PSO is a kind of population-based searching procedure that uses the particles to change their position in the problem space, which is shown in below:

$$
V_{i}^{k+1} \omega^{k} V_{i}^{k}+a_{1} r_{1} \times\left(P_{b i}^{k}-X_{i}^{k}\right)+a_{2} r_{2} \times\left(G_{b i}^{k}-X_{i}^{k}\right)
$$

where $P_{b i}$ represents the local best particle, $G_{b i}$ indicates the global best particle, $\omega$ indicates the inertia weight function, $a_{1}$ and $a_{2}$ are the acceleration constants and $r_{1}$ and $r_{2}$ are the random values that lies between 0 and 1 . The particle's position is updated as follows:

$$
X_{i}^{k+1}=X_{i}^{k}+V_{i}^{k+1}
$$

The search space in PSO is multi-dimensional in nature, in which each particle and its position are updated based on the experience of neighboring particles. The procedure of PSO is illustrated as follows:

\section{Algorithm I - Particle Swarm Optimization \\ Step 1: Input the system parameters such as wind specification, voltage limit, line data, bus data and line limits;}

Step 2: Initialize the PSO settings;

Step 3: Set the iteration counter $c=0$, where the population of particles is initialized with random positions and velocities on dimensions;

Step 4: For each particle, the objective function is calculated and compared with the individual best value. Based on this, the best $P_{b}$ value is modified with the higher value, and the current position of the particle is recorded;

Step 5: Choose the particle that associated with the individual best $P_{b}$ of all particles, and set the value of $P_{b}$ as the overall $G_{b}$;

Step 6: Update the velocity and position of each particle;

Step 7: If the number of iterations reach the maximum limit, go to Step 8; otherwise, set the iteration index as $c=$ $c+1$ and go to Step 4;

Step 8: The best particle denoted by $G_{b}$ provides the optimal solution for the problem;

\section{Case study}

The proposed system is tested based on the following case studies: 


\section{Renewable resources integrated with IEEE 14-bus system}

This system contains three synchronous generators connected at the buses 1, 2 and 8, where the automatic voltage regulator (AVR) and turbine governors of type II are connected with the sixth-order model generators at buses 1 and 2 . The wind farm placement index calculation assumed that wind farm was located at an equidistant point from all the buses and identified bus 3 as the most suitable bus, and accordingly, the variable speed wind turbine generating system with DFIG is placed at bus 3 through a transformer and bus 15 (Sreedharan et al. 2010). The wind is modeled based on its composite nature, which includes average, ramp, gust and turbulence components. Moreover, a solar photovoltaic generator is integrated at bus 6 through a transformer and bus 16; then, the bus 11 is modified by adding a synchronous generator through a transformer and bus 17 for representing the power generation from bio mass. The single-line diagram of the IEEE 14-bus system connected with the solar and wind power model is shown in Fig. 2.

\section{Renewable resources integrated with Kerala grid}

This system contains four synchronous generators connected at the buses 3 (Brahmapuram), 6 (Idukki), 17 (Nallalam) and 24 (Sabarigiri). The AVR and turbine governors are connected with the generators; then, the DFIG is placed at the buses 1 (Agali) and 23 (Ramakkalmedu). Similarly, two solar photovoltaic generators are integrated at the buses 4 (CASF) and 11 (KSEBSF). The single-line diagram of the Kerala grid with wind and solar power modeled is depicted in Fig. 3.

\section{Results and discussions}

This section presents the experimental results of the proposed system design with two cases studied. The parameters that used to evaluate the results are real power generation, bus voltage and real power load.

\section{Case study 1}

Figure 4 shows the flow of maximization process. Twenty-four dependent variables are considered, and they are the voltages and angles of generator buses (7

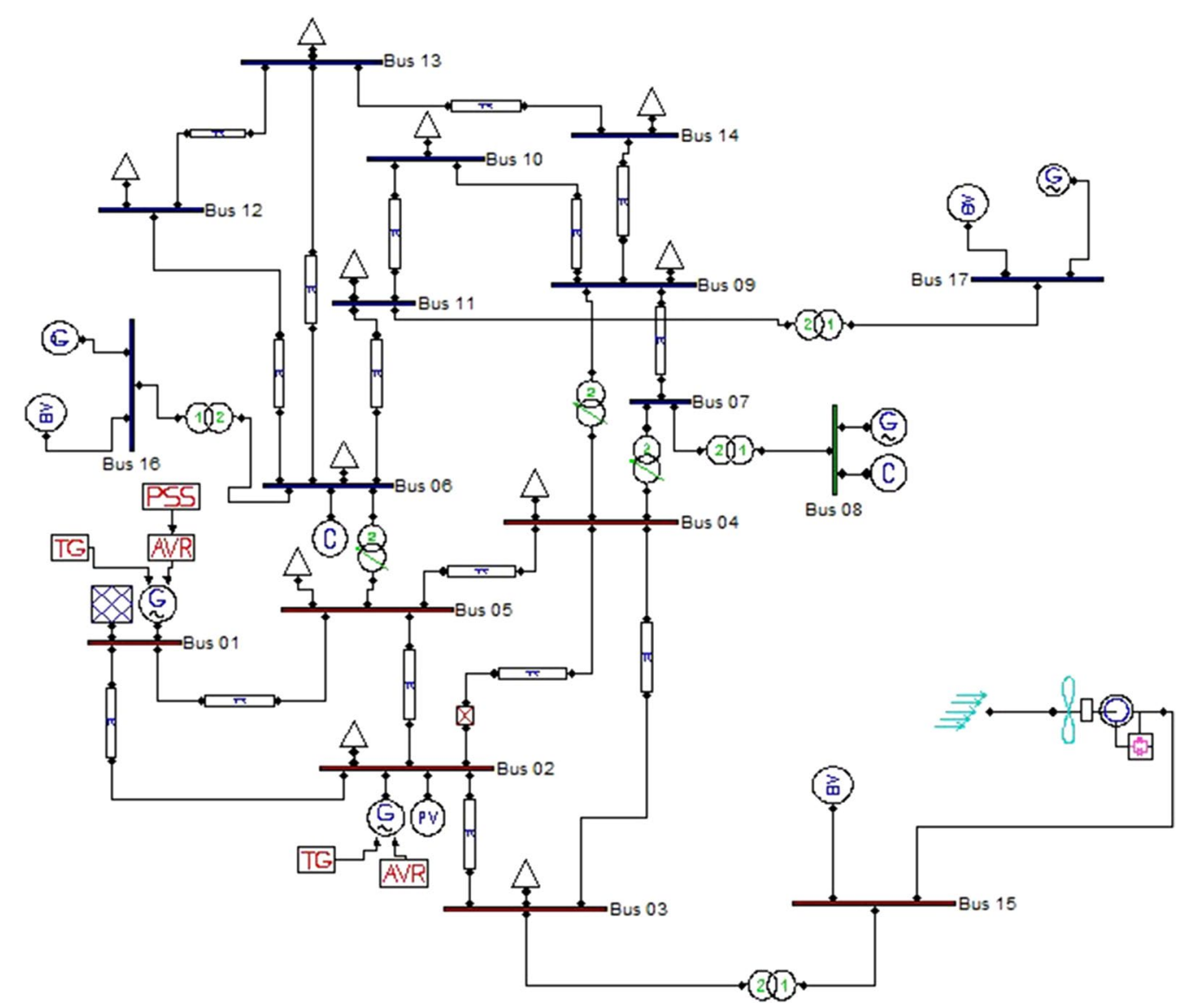

Fig. 2 Renewable energy sources integrated with IEEE 14-bus system 

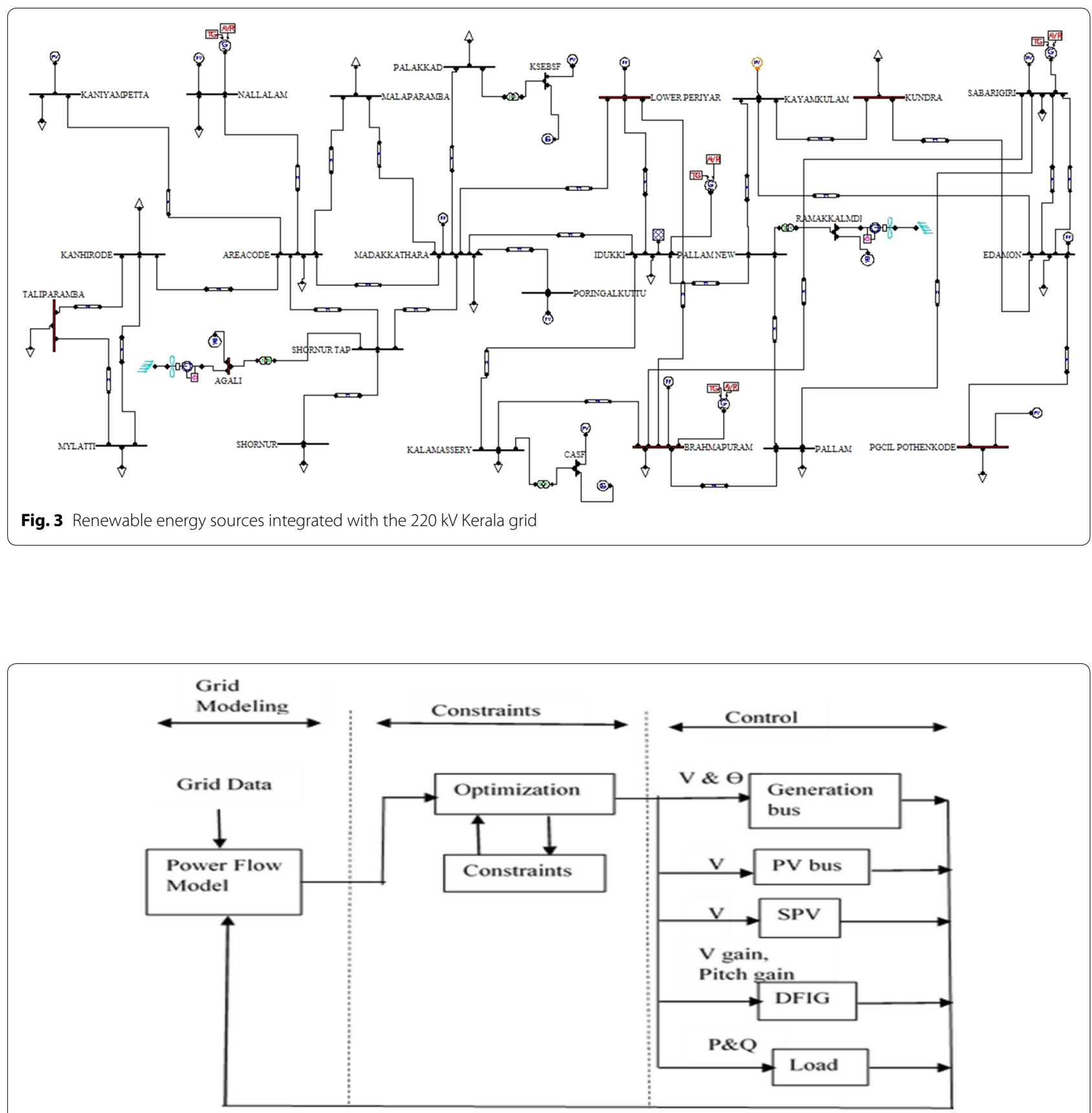

Fig. 4 The flow of maximization process 

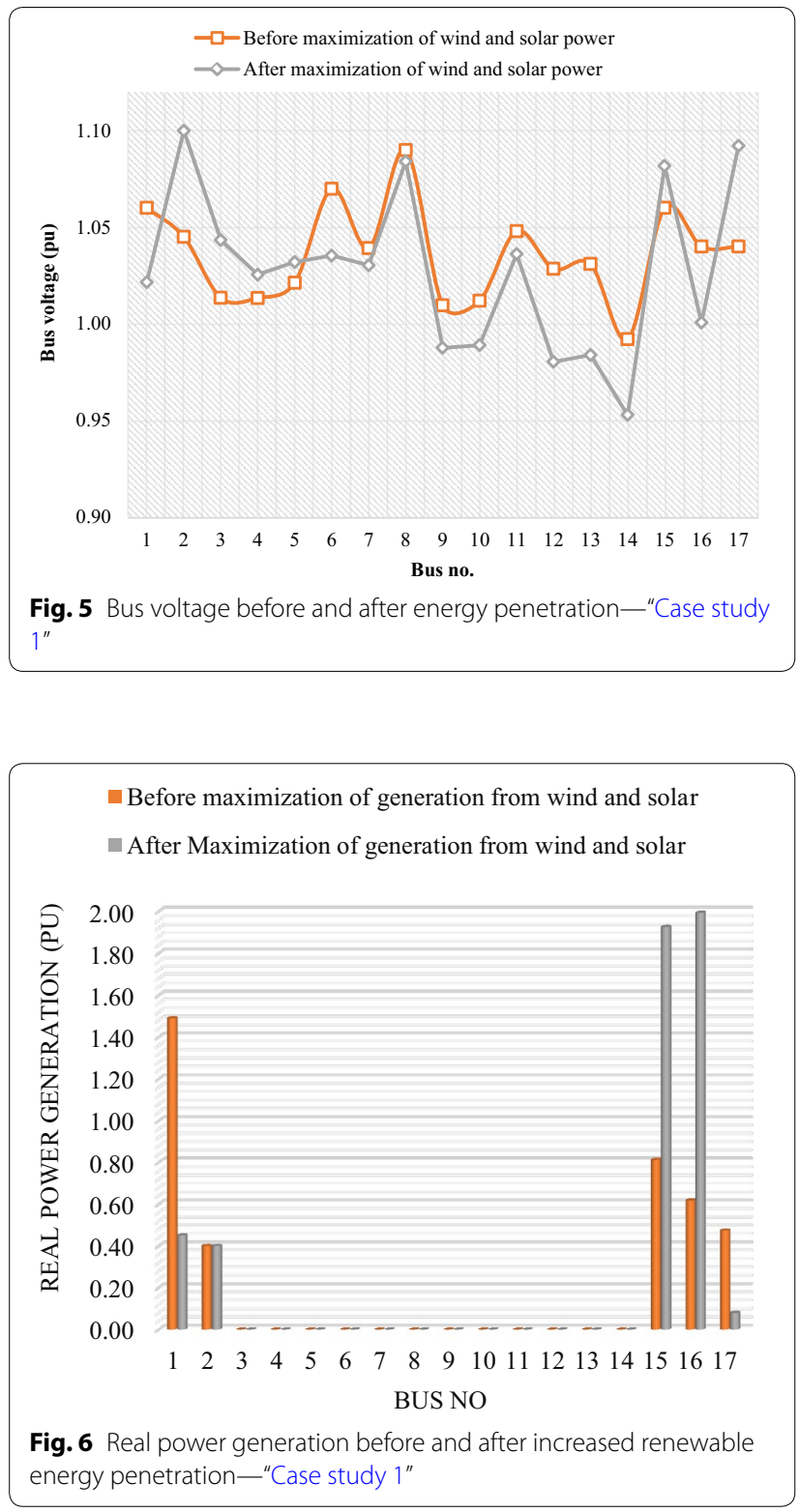

variables), voltages of PV bus (3 variables), voltage gain and pitch gain of DFIG (2 variables), voltage of SPV (1 variable) and loads (11 variables). Figures 5, 6 and 7 compare the results of bus voltage, real power generation, and real power load of the IEEE 14-bus system before and after maximization of renewable energy generation. Before maximizing the generation, the total

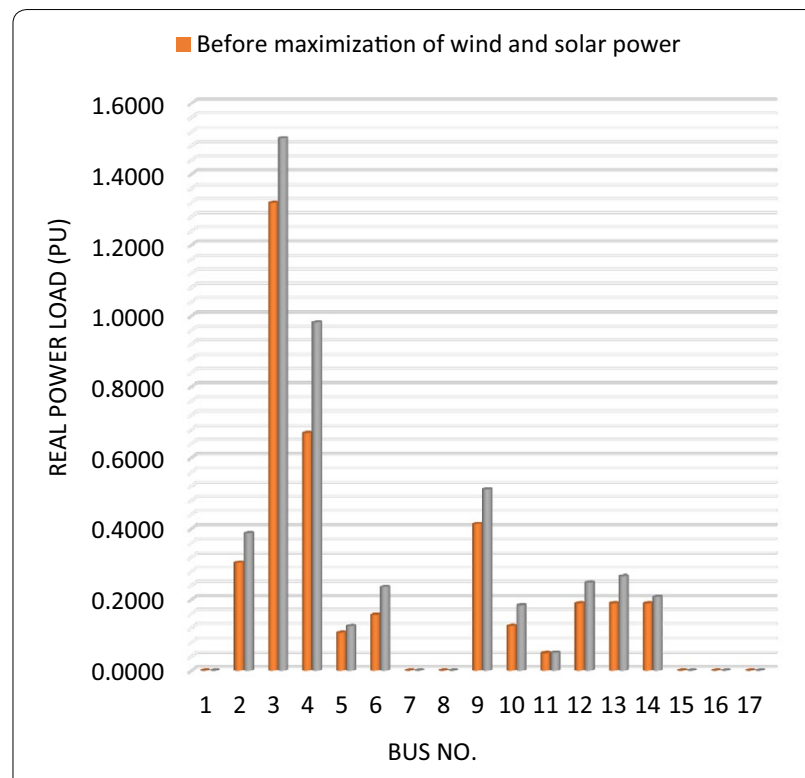

Fig. 7 Real power load before and after increased renewable energy penetration- "Case study 1"

power generation of the IEEE 14-bus system is 3.7962 p.u. (i.e., $379.62 \mathrm{MW}$ ), in which the total share from the wind and solar sources is 1.4316 p.u. (i.e., $143.16 \mathrm{MW}$ ). After maximization, the energy penetration of solar and wind sources is increased to 3.9204 p.u. (392.04 MW) out of total generation of 4.8512 p.u. (485.12 MW). The share from renewable resources increased to $80 \%$ which was only $37 \%$ initially. The generation share from conventional sources has been replaced by the renewable resources. The power flow configuration of the IEEE 14-bus system is shown in Table 1.

The damping ratio is used to analyze the small signal stability of the system. Table 2 illustrates the eigenvalues, damping ratios and the most associated states of the IEEE 14-bus system before and after maximization of wind and solar generation. Here, for both the situations, there are 42 eigenvalues, all of them having negative real parts which indicate that the system is stable. Before maximizing the generation share from renewable resources, out of the 42 eigenvalues, 7 are complex eigenpairs with damping ratio less than 1 , where the lowest damping ratio is 0.118 . After maximizing the generation from renewable resources, out of the 42 eigenvalues, 6 are complex 
Table 1 Power flow IEEE 14 bus

\begin{tabular}{|c|c|c|c|c|c|c|c|c|c|}
\hline \multirow[t]{2}{*}{ Bus no } & \multicolumn{5}{|c|}{ Base case } & \multicolumn{4}{|c|}{$\begin{array}{l}\text { After maximization of renewable energy } \\
\text { generation }\end{array}$} \\
\hline & Voltage & $P_{\text {gen }}$ & $Q_{\text {gen }}$ & $P_{\text {Load }}$ & $Q_{\text {load }}$ & Voltage & $P_{\text {gen }}$ & $Q_{\text {gen }}$ & $P_{\text {Load }}$ \\
\hline 1 & 1.06 & 1.4902 & -0.0025 & 0 & 0 & 1.0215 & 0.45102 & -1.572 & 0 \\
\hline 2 & 1.0450 & 0.4 & 0.3863 & 0.3038 & 0.178 & 1.1 & 0.4 & 2.80 & 0.387 \\
\hline 3 & 1.0134 & 0 & 0 & 1.319 & 0.266 & 1.0434 & 0 & 0 & 1.501 \\
\hline 4 & 1.0133 & 0 & 0 & 0.669 & 0.056 & 1.0254 & 0 & 0 & 0.9813 \\
\hline 5 & 1.0212 & 0 & 0 & 0.106 & 0.022 & 1.0319 & 0 & 0 & 0.1257 \\
\hline 6 & 1.0700 & 0 & 0.5886 & 0.157 & 0.105 & 1.0353 & 0 & 0.5168 & 0.235 \\
\hline 7 & 1.0392 & 0 & 0 & 0 & 0 & 1.0303 & 0 & 0 & 0 \\
\hline 8 & 1.09 & 0 & 0.3142 & 0 & 0 & 1.0841 & 0 & 0.3313 & 0 \\
\hline 9 & 1.0095 & 0 & 0 & 0.413 & 0.2324 & 0.9875 & 0 & 0 & 0.510 \\
\hline 10 & 1.0119 & 0 & 0 & 0.126 & 0.0812 & 0.989 & 0 & 0 & 0.1836 \\
\hline 11 & 1.0480 & 0 & 0 & 0.049 & 0.0252 & 1.036 & 0 & 0 & 0.049 \\
\hline 12 & 1.0284 & 0 & 0 & 0.189 & 0.0812 & 0.980 & 0 & 0 & 0.2478 \\
\hline 13 & 1.0309 & 0 & 0 & 0.189 & 0.0812 & 0.984 & 0 & 0 & 0.266 \\
\hline 14 & 0.9919 & 0 & 0 & 0.189 & 0.0812 & 0.953 & 0 & 0 & 0.2077 \\
\hline 15 & 1.06 & 0.8134 & 0.3349 & 0 & 0 & 1.082 & 1.9264 & 0.5326 & 0 \\
\hline 16 & 1.04 & 0.6182 & -0.1468 & 0 & 0 & 1.0006 & 1.994 & 0.1512 & 0 \\
\hline 17 & 1.04 & 0.4744 & -0.0290 & 0 & 0 & 1.092 & 0.0798 & 0.349 & 0 \\
\hline
\end{tabular}

Table 2 The eigenvalues, damping ratios and associated states of the IEEE 14 bus system before and after maximization with solar and wind power

\begin{tabular}{|c|c|c|c|c|c|c|c|}
\hline \multicolumn{4}{|c|}{ Before maximization with solar and wind power } & \multicolumn{4}{|c|}{ After maximization with wind and solar power } \\
\hline $\begin{array}{l}\text { Eigen } \\
\text { numbers }\end{array}$ & Eigenvalues & Damping ratio & $\begin{array}{l}\text { Most associated } \\
\text { states }\end{array}$ & $\begin{array}{l}\text { Eigen } \\
\text { numbers }\end{array}$ & Eigen values & $\begin{array}{l}\text { Damping } \\
\text { ratio }\end{array}$ & $\begin{array}{l}\text { Associated } \\
\text { states }\end{array}$ \\
\hline 1 & -1000 & 1 & $v m_{-} E x c_{-} 2$ & 1 & -1000 & 1 & vm_Exc_2 \\
\hline 2 & -1000 & 1 & vm_Exc_1 & 2 & -1000 & 1 & vm_Exc_1 \\
\hline 3 & -99.2985 & 1 & iqr_Dfig_1 & 3 & -92.859 & 1 & iqr_Dfig_1 \\
\hline 4 & -73.0801 & 1 & iq_Spv_1 & 4 & -68.3848 & 1 & iq_Spv_1 \\
\hline 5 & -53.4892 & 1 & id_Spv_1 & 5 & -56.1733 & 1 & id_Spv_1 \\
\hline 6 & -49.9798 & 1 & vr1_Exc_2 & 6 and 7 & $-44.4131 \pm 7.7136 i$ & 0.985 & $\begin{array}{l}\text { vr1_Exc_1, } \\
\text { e2q_Syn_1, } \\
\text { vf_Exc_1 }\end{array}$ \\
\hline 7 and 8 & $-44.0346 \pm 8.2427 i$ & 0.983 & $\begin{array}{l}\text { vr1_Exc_1, } \\
\text { e2q_Syn_2 }\end{array}$ & 8 & -36.7227 & 1 & $\begin{array}{l}\text { e2d_Syn_1, } \\
\text { e2d_Syn_2 }\end{array}$ \\
\hline 9 & -37.0999 & 1 & e2d_Syn_1 & 9 & -33.2848 & 1 & e2q_Syn_2 \\
\hline 10 & -33.1002 & 1 & e2q_Syn_2 & 10 & -25.6455 & 1 & e2q_Syn_3 \\
\hline 11 & -25.6419 & 1 & e2q_Syn_3 & 11 & -22.3182 & 1 & e2q_Syn_4 \\
\hline 12 & -21.3858 & 1 & e2q_Syn_4 & 12 & -17.855 & 1 & $\begin{array}{l}\text { e2d_Syn_2, } \\
\text { e1d_Syn_2 }\end{array}$ \\
\hline 13 & -16.7754 & 1 & e2d_Syn_2 & 13 and 14 & $-2.2759 \pm 11.6701 i$ & 0.191 & $\begin{array}{c}\text { omega_Syn_2, } \\
\text { delta_Syn_2 }\end{array}$ \\
\hline 14 and 15 & $-3.3659 \pm 9.8278 i$ & 0.324 & $\begin{array}{c}\text { omega_Syn_3, } \\
\text { delta_Syn_3 }\end{array}$ & 15 and 16 & $-3.1892 \pm 9.8849 i$ & 0.307 & $\begin{array}{r}\text { omega_Syn_3, } \\
\text { delta_Syn_3 }\end{array}$ \\
\hline 16 and 17 & $-1.1061 \pm 9.3197 i$ & 0.118 & $\begin{array}{l}\text { e1q_Syn_1, } \\
\text { vf_Exc_1 }\end{array}$ & 17 and 18 & $-0.74009 \pm 9.4357 i$ & 0.078 & $\begin{array}{l}\text { e1q_Syn_1, } \\
\text { vf_Exc_1 }\end{array}$ \\
\hline 18 and 19 & $-2.9434 \pm 8.7538 i$ & 0.319 & $\begin{array}{c}\text { omega_Syn_2, } \\
\text { delta_Syn_2 }\end{array}$ & 19 and 20 & $-1.3519 \pm 7.3681 i$ & 0.18 & $\begin{array}{c}\text { omega_Syn_4, } \\
\text { delta_Syn_4, } \\
\text { e2d_Syn_4 }\end{array}$ \\
\hline
\end{tabular}


Table 2 (continued)

\begin{tabular}{|c|c|c|c|c|c|c|c|}
\hline \multicolumn{4}{|c|}{ Before maximization with solar and wind power } & \multicolumn{4}{|c|}{ After maximization with wind and solar power } \\
\hline $\begin{array}{l}\text { Eigen } \\
\text { numbers }\end{array}$ & Eigenvalues & Damping ratio & $\begin{array}{l}\text { Most associated } \\
\text { states }\end{array}$ & $\begin{array}{l}\text { Eigen } \\
\text { numbers }\end{array}$ & Eigen values & $\begin{array}{l}\text { Damping } \\
\text { ratio }\end{array}$ & $\begin{array}{l}\text { Associated } \\
\text { states }\end{array}$ \\
\hline 20 and 21 & $-1.0872 \pm 7.5138 i$ & 0.143 & $\begin{array}{c}\text { omega_Syn_4, } \\
\text { delta_Syn_4 }\end{array}$ & 21 & -11.8806 & 1 & $\begin{array}{l}\text { e2d_Syn_3, } \\
\text { delta_Syn_3, } \\
\text { omega_ } \\
\text { Syn_3 }\end{array}$ \\
\hline 22 & -12.0538 & 1 & e2d_Syn_3 & 22 & -11.0187 & 1 & $\begin{array}{l}\text { btx1_Spv_1, } \\
\text { e2d_Syn_4, }\end{array}$ \\
\hline 23 and 24 & $-10.459 \pm 0.03002 i$ & 1 & $\begin{array}{l}\text { btx1_Spv_1, } \\
\text { e2d_Syn_4 }\end{array}$ & 23 & -9.6637 & 1 & $\begin{array}{l}\text { tg_Tg_2,e1d_ } \\
\text { Syn_2, } \\
\text { e2d_Syn_2 }\end{array}$ \\
\hline 25 & -9.5669 & 1 & tg_Tg_2 & 24 & -9.1454 & 1 & $\begin{array}{l}\text { tg_Tg_1, } \\
\text { e2d_Syn_4, } \\
\text { omega_Syn_ }\end{array}$ \\
\hline 26 & -8.9995 & 1 & tg_Tg_1 & 25 & -8.5301 & 1 & $\begin{array}{l}\text { e2d_Syn_4, } \\
\text { e1d_Syn_2 }\end{array}$ \\
\hline 27 & -7.4985 & 1 & e1d_Syn_2 & 26 & -8.3408 & 1 & $\begin{array}{l}\text { e1d_Syn_2, } \\
\text { e2d_Syn_2, }\end{array}$ \\
\hline 28 and 29 & $-0.50581 \pm 1.9977 i$ & 0.245 & $\begin{array}{c}\text { omega_Syn_1, } \\
\text { delta_Syn_1 }\end{array}$ & 27 and 28 & $-0.34253 \pm 2.2326 i$ & 0.0757 & $\begin{array}{c}\text { omega_Syn_1, } \\
\text { delta_Syn_1 }\end{array}$ \\
\hline 30 & -2.5454 & 1 & idr_Dfig_1 & 29 & -2.8708 & 1 & idr_Dfig_1 \\
\hline 31 & -0.24538 & 1 & e1q_Syn_4 & 30 & -0.68888 & 1 & $\begin{array}{l}\text { e1q_Syn_4, } \\
\text { e1d_Syn_4 }\end{array}$ \\
\hline 32 and 33 & $-0.56184 \pm 0.38565$ & 0.824 & $\begin{array}{l}\text { e1q_Syn_2, } \\
\text { vf_Exc_2 }\end{array}$ & 31 & -0.99054 & 1 & $\begin{array}{l}\text { omega_m_ } \\
\text { Dfig_1 }\end{array}$ \\
\hline 34 & -0.79035 & 1 & $\begin{array}{l}\text { omega_m_ } \\
\text { Dfig_1 }\end{array}$ & 32 & -1.0116 & 1 & vr2_Exc_1 \\
\hline 35 & -0.89037 & 1 & e1d_Syn_3 & 33 & -0.82144 & 1 & $\begin{array}{c}\text { e1q_Syn_2, } \\
\text { e1d_Syn_4, } \\
\text { e1q_Syn_3 }\end{array}$ \\
\hline 36 & -0.89365 & 1 & e1q_Syn_3 & 34 & -0.83365 & 1 & $\begin{array}{l}\text { e1q_Syn_2, } \\
\text { e1d_Syn_4 }\end{array}$ \\
\hline 37 & -1.0228 & 1 & vr2_Exc_1 & 35 & -0.89925 & 1 & e1d_Syn_3 \\
\hline 38 & -1.0181 & 1 & e1d_Syn_4 & 36 & -0.90227 & 1 & e1q_Syn_3 \\
\hline 39 & -1.0092 & 1 & vr2_Exc_2 & 37 & -30.303 & 1 & e1d_Syn_1 \\
\hline 40 & -1.25 & 1 & e1d_Syn_1 & 38 & -50 & 1 & vr1_Exc_2 \\
\hline 41 & -0.25 & 1 & vw_Wind_1 & 39 & -1 & 1 & vr2_Exc_2 \\
\hline \multirow[t]{3}{*}{42} & -0.33333 & 1 & theta_P_Dfig_1 & 40 & -0.78592 & 1 & vf_Exc_2 \\
\hline & & & & 41 & -0.25 & 1 & vw_Wind_1 \\
\hline & & & & 42 & -0.33333 & 1 & theta_p_Dfig_1 \\
\hline
\end{tabular}

eigenpairs and the lowest damping ratio is 0.0757 . The values of damping ratios indicate that the system is stable after increasing the generation share from renewable resources, but the degree of small signal stability of the system decreased slightly.
In order to improve the small signal stability, the optimization of the damping ratio of IEEE 14-bus system with increased penetration of wind and solar power is performed. The dependent variables in the optimization are the exciter amplifier gain Ka, exciter stabilizer gain 
Table 3 The eigenvalues, damping ratios and associated states of the IEEE 14-bus system after optimization of damping ratios

\begin{tabular}{|c|c|c|c|}
\hline Eigennumbers & Eigenvalues & Damping ratio & Most associated states and $\%$ participation \\
\hline 1 & -1000 & 1 & vm_Exc_1 (100) \\
\hline 2 & -1000 & 1 & vm_Exc_2(100) \\
\hline 3 & -92.859 & 1 & iqr_Dfig_1 (99.34) \\
\hline 4 & -68.3848 & 1 & iq_Spv_1 (91.43) \\
\hline 5 & -56.1733 & 1 & id_Spv_1 (87.85) \\
\hline 6 and 7 & $-36.8065 \pm 0.48647 i$ & 1 & e2d_Syn_1 (44.55), e2q_Syn_1(33.61), btx1_Spv_1 (11.96) \\
\hline 8 & -31.6088 & 1 & e2q_Syn_2 (69.99), e2q_Syn_1 (25.907) \\
\hline 9 & -25.5361 & 1 & e2q_Syn_3 (91.47) \\
\hline 10 & -22.2968 & 1 & e2q_Syn_4 (93.12) \\
\hline 11 & -17.7616 & 1 & e2d_Syn_2(62.395), e1d_Syn_2(23.52) \\
\hline 12 and 13 & $-2.9492 \pm 8.75306 i$ & 0.32 & omega_Syn_2 (32.30), delta_Syn_2 (31.98), e2d_Syn_2 (8.667) \\
\hline 14 and 15 & $-3.1789 \pm 9.9343 i$ & 0.305 & omega_Syn_3 (31.437), delta_Syn_3 (31.26), e2d_Syn_3 (18.58) \\
\hline 16 and 17 & $-1.5058 \pm 7.6511 i$ & 0.193 & $\begin{array}{l}\text { Omega_Syn_4 (29.485), delta_Syn_4(29.35), e2d_Syn_4 (12.10), omega_Syn_1 (10.872), } \\
\text { delta_Syn_1 (6.35) }\end{array}$ \\
\hline 18 & -11.8927 & 1 & $\begin{array}{l}\text { e2d_Syn_3 (51.98), omega_Syn_3 (10.573), delta_Syn_3 (10.397), e2d_Syn_4 (8.778), } \\
\text { btx1_Spv_1(7.17) }\end{array}$ \\
\hline 19 & -11.0105 & 1 & $\begin{array}{l}\text { btx1_Spv_1(52.368), e2d_Syn_4(18.063), id_Spv_1 (7.79), e2d_Syn_3(5.746), omega_ } \\
\text { Syn_4(5.193), delta_Syn_4 (5.1) }\end{array}$ \\
\hline 20 & -9.9229 & 1 & $\operatorname{tg} \_T g \_2(96.44)$ \\
\hline 21 & -8.6679 & 1 & $\begin{array}{l}\text { e2d_Syn_4 (51.276), btx1_Spv_1 (5.006), omega_Syn_4 (8.692), delta_Syn_4 (8.494), } \\
\text { e2d_Syn_2 (6.209) }\end{array}$ \\
\hline 22 & -8.4751 & 1 & e1d_Syn_2 (52.62), e2d_Syn_2 (23.58), e2d_Syn_4 (14.13) \\
\hline 23 and 24 & $-1.8633 \pm 3.0534 i$ & 0.521 & omega_Syn_1(35.656), tg_Tg_1 (25.193), delta_Syn_1 (16.667) \\
\hline 25 and 26 & $-3.3114 \pm 0.03738 i$ & 1 & tg_Tg_1 (30.535), omega_Syn_1(25.6), delta_Syn_1 (16.95) \\
\hline 27 & -0.18505 & 1 & e1q_Syn_1 (96.726) \\
\hline 28 & -0.68776 & 1 & e1q_Syn_4 (82.208), e1d_Syn_4 (12.12) \\
\hline 29 & -0.79842 & 1 & e1q_Syn_2 (79.609), e1q_Syn_3 (5.727), e1d_Syn_4(7.635) \\
\hline 30 & -0.83005 & 1 & e1d_Syn_4 (73.221), e1q_Syn_4 (11.83) \\
\hline 31 & -0.85987 & 1 & omega_m_Dfig_1(67.974), delta_Syn_1(15.07) \\
\hline 32 & -0.90239 & 1 & e1q_Syn_3(86.856) \\
\hline 33 & -0.89951 & 1 & e1d_Syn_3 (94.42) \\
\hline 34 & -30.303 & 1 & e1d_Syn_1(100) \\
\hline 35 & -1 & 1 & vr2_Exc_1(100) \\
\hline 36 & -5.0106 & 1 & vf_Exc_1(100) \\
\hline 37 & -50 & 1 & vr1_Exc_1(100) \\
\hline 38 & -50 & 1 & vr1_Exc_2(100) \\
\hline 39 & -1 & 1 & vr2_Exc_2 (100) \\
\hline 40 & -0.78592 & 1 & vf_Exc_2 (100) \\
\hline 41 & -0.25 & 1 & vw_Wind_1 (100) \\
\hline 42 & -0.33333 & 1 & theta_p_Dfig_1(100) \\
\hline
\end{tabular}


Table 4 Comparison of damping ratios-IEEE 14-bus system with wind and solar power

\begin{tabular}{|c|c|c|c|}
\hline \multirow[t]{2}{*}{ Most associated states } & \multicolumn{3}{|l|}{ Damping ratio } \\
\hline & $\begin{array}{l}\text { Before maximization of wind } \\
\text { and solar power }\end{array}$ & $\begin{array}{l}\text { After maximization of wind } \\
\text { and solar power }\end{array}$ & After optimization of damping ratio \\
\hline vr1_Exc_1, e2q_Syn_2 & 0.983 & 0.985 & 1 \\
\hline omega_Syn_3, delta_Syn_3 & 0.324 & 0.307 & 0.324 \\
\hline e1q_Syn_1,vf_Exc_1 & 0.118 & 0.078 & 1 \\
\hline omega_Syn_2,delta_Syn_2 & 0.319 & 0.191 & 0.32 \\
\hline omega_Syn_4,delta_Syn_4 & 0.143 & 0.18 & 0.193 \\
\hline omega_Syn_1,delta_Syn_1 & 0.245 & 0.0757 & 0.521 \\
\hline e1q_Syn_2,vf_Exc_2 & 0.824 & 1 & 1 \\
\hline
\end{tabular}

$K_{f}$ and turbine governor droop $R$. Table 3 illustrates the eigenvalues, damping ratio and the most associated states along with the percentage participation after optimizing the damping ratios. There are 42 eigenvalues as before, all having negative real parts out of which there are only 4 complex eigenpairs.

Table 4 depicts the comparison of damping ratios before and after maximization of power generation from wind and solar resources and after optimization of damping ratio. A comparison of the damping ratios of corresponding complex eigenvalues is shown in Fig. 8, which clearly indicates the improvement in the small signal stability.

\section{Case Study 2}

The initial total generation of the Kerala grid system is 17.3046 p.u. (1730.46 MW). The power generation from the wind and solar sources is 1.8507 p.u. (185 MW). The power flow results before and after maximizing the renewable penetration (the penetration of wind power is

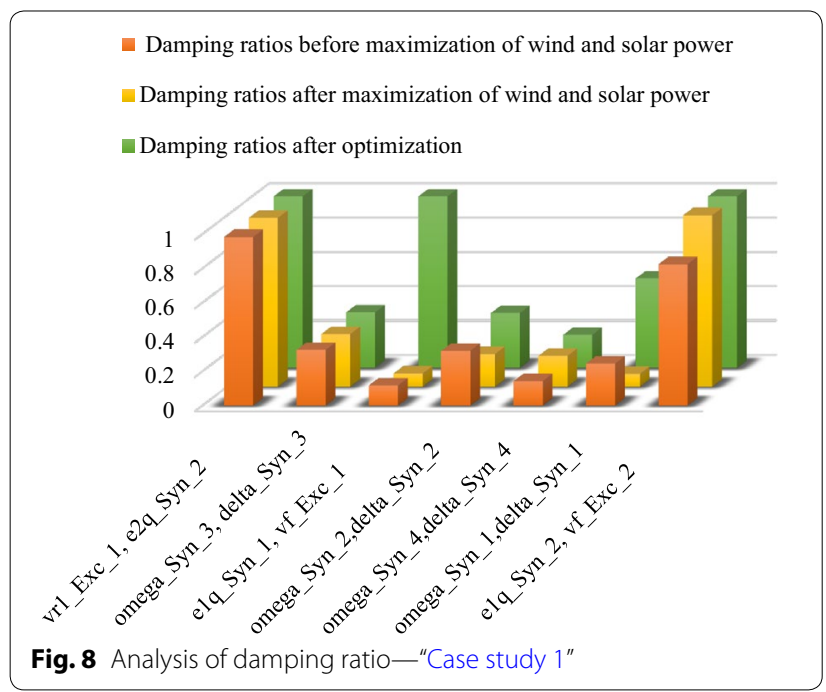

maximized here considering the existing installed capacity) are given in Table 5.

The total generation from the renewable resources has been increased to 4.7324 p.u. (473 MW) after stage I. Figures 9, 10 and 11 show the comparative analysis of the real power generation, voltage and loads (in per unit) before and after maximizing the generation share from renewable resources.

Before maximization of renewable generation, the Kerala grid have 64 eigenvalues, all having negative real parts, and there are 10 complex eigenpairs. The minimum damping ratio obtained is 0.0371 . After maximization of renewable generation share, there are 6 complex eigenpairs. Table 6 gives a comparison of complex eigenvalues, damping ratios and most associated states of the Kerala grid before and after maximization of generation from wind power and also after the optimization of damping ratios.

The optimization of the damping ratio of Kerala grid with maximum penetration of wind power is performed to increase the small signal stability. The dependent variables taken for optimizing the damping ratios are the exciter amplifier gain $K_{\mathrm{a}}$, exciter stabilizer gain $K_{f}$ and turbine governor droop $R$. There were 64 eigenvalues as before, all having negative real parts, and there are only 4 complex eigenpairs. Figure 12 shows the comparative analysis of the damping ratios for the three conditions. From the evaluation, it is observed that the renewable energy penetration into the Kerala grid can be increased maintaining the small signal stability using the proposed method.

\section{Conclusion}

This paper developed a multistage optimization technique for improving the renewable energy penetration and optimizing the small signal stability. Here, the PSO is utilized to optimize the parameters for maximizing the renewable integration with small signal stability. 
Table 5 Power flow from Kerala grid

\begin{tabular}{|c|c|c|c|c|c|c|c|c|c|c|c|}
\hline \multirow{2}{*}{ Bus no. } & \multirow[t]{2}{*}{ Name } & \multicolumn{5}{|c|}{ Before maximizing renewable generation } & \multicolumn{5}{|c|}{ After maximizing renewable generation } \\
\hline & & Voltage & $P_{\text {gen }}$ & $Q_{\text {gen }}$ & $P_{\text {Load }}$ & $Q_{\text {load }}$ & Voltage & $P_{\text {gen }}$ & $Q_{\text {gen }}$ & $P_{\text {Load }}$ & $Q_{\text {load }}$ \\
\hline 1 & AGGALI & 1.02 & 0 & -0.0068 & 0 & 0 & 1.068 & 0.0022 & -0.0072 & 0 & 0 \\
\hline 2 & AREACODE & 1.0297 & 0 & 0 & 0.08 & 0.06 & 1.051 & 0 & 0 & 0.08 & 0.06 \\
\hline 3 & BRAHMAPURAM & 1.04 & 0.81 & 3.1378 & 0.81 & 0.607 & 1.1 & 0.81 & 11.503 & 1.01 & 0.75 \\
\hline 4 & CASF & 1.06 & 0.73 & 0.1407 & 0 & 0 & 1.061 & 0.73 & -0.0876 & 0 & 0 \\
\hline 5 & EDAMON & 1.04 & 0.78 & 2.6862 & 1.46 & 1.095 & 1.1 & 0.78 & 11.163 & 2.19 & 1.64 \\
\hline 6 & IDUKKI & 1.06 & 4.51 & 5.8555 & 0.04 & 0.03 & 1.002 & 7.3575 & -9.011 & 0.05 & 0.039 \\
\hline 7 & KALAMASSERY & 1.0356 & 0 & 0 & 2.55 & 1.912 & 1.079 & 0 & 0 & 3.73 & 2.797 \\
\hline 8 & KANHIRODE & 0.9756 & 0 & 0 & 0.7 & 0.525 & 0.990 & 0 & 0 & 0.79 & 0.594 \\
\hline 9 & KANIYAMPETTA & 1.02 & 0.13 & -0.0328 & 0.2 & 0.15 & 1.1 & 0.13 & 1.0605 & 0.20 & 0.150 \\
\hline 10 & KAYAMKULAM & 1.0203 & 0 & 0 & 0 & 0 & 1.043 & 0 & 0 & 0 & 0 \\
\hline 11 & KSEBSF & 1.06 & 0.73 & 0.4053 & 0 & 0 & 1.008 & 0.73 & -0.1044 & 0 & 0 \\
\hline 12 & KUNDRA & 0.994 & 0 & 0 & 1.2 & 1.15 & 1.018 & 0 & 0 & 1.8 & 1725 \\
\hline 13 & LOWER PERIYAR & 1.02 & 1.8 & -6.0147 & 0 & 0 & 1.037 & 1.8 & -0.2709 & 0 & 0 \\
\hline 14 & MADAKKATHARA & 1.04 & 3.84 & 3.3687 & 1.7 & 1.275 & 1.1 & 3.84 & 9.9387 & 1.79 & 1.347 \\
\hline 15 & MALAPARAMBA & 1.0315 & 0 & 0 & 0.2 & 0.15 & 1.072 & 0 & 0 & 0.24 & 0.182 \\
\hline 16 & MYLATTI & 0.9648 & 0 & 0 & 0.5 & 0.375 & 0.978 & 0 & 0 & 0.56 & 0.418 \\
\hline 17 & NALLALAM & 1.04 & 0.73 & 1.5645 & 0.86 & 0.645 & 1.028 & 0.73 & -1.4312 & 0.86 & 0.645 \\
\hline 18 & PALAKKAD & 0.9858 & 0 & 0 & 2.1 & 1.575 & 1.032 & 0 & 0 & 2.10 & 1.578 \\
\hline 19 & PALLAM & 1.0104 & 0 & 0 & 2.51 & 1.882 & 1.015 & 0 & 0 & 3.76 & 2.824 \\
\hline 20 & PALLAM NEW & 1.0159 & 0 & 0 & 0 & 0 & 1.018 & 0 & 0 & 0 & 0 \\
\hline 21 & PGCIL POTHENKODE & 1.04 & 0 & 1.3855 & 1.47 & 1.102 & 1.0 & 0 & -2.8687 & 2.20 & 1.65 \\
\hline 22 & PORINGALKUTTU & 1.04 & 0.32 & -0.081 & 0 & 0 & 1.055 & 0.32 & -1.2086 & 0 & 0 \\
\hline 23 & RAMAKKALMED & 1.02 & 0.39 & 0.0161 & 0 & 0 & 1.1 & 3.2702 & 1.2959 & 0 & 0 \\
\hline 24 & SABARIGIRI & 1.04 & 2.53 & 0.0906 & 0.16 & 0.12 & 1.097 & 2.53 & 1.0058 & 0.23 & 0.173 \\
\hline 25 & SHORNUR & 1.0317 & 0 & 0 & 0.3 & 0.225 & 1.078 & 0 & 0 & 0.3 & 0.225 \\
\hline 26 & SHORNURTAP & 1.032 & 0 & 0 & 0 & 0 & 1.078 & 0 & 0 & 0 & 0 \\
\hline 27 & TALIPARAMBA & 0.9694 & 0 & 0 & 0.2 & 0.15 & 0.983 & 0 & 0 & 0.22 & 0.166 \\
\hline
\end{tabular}

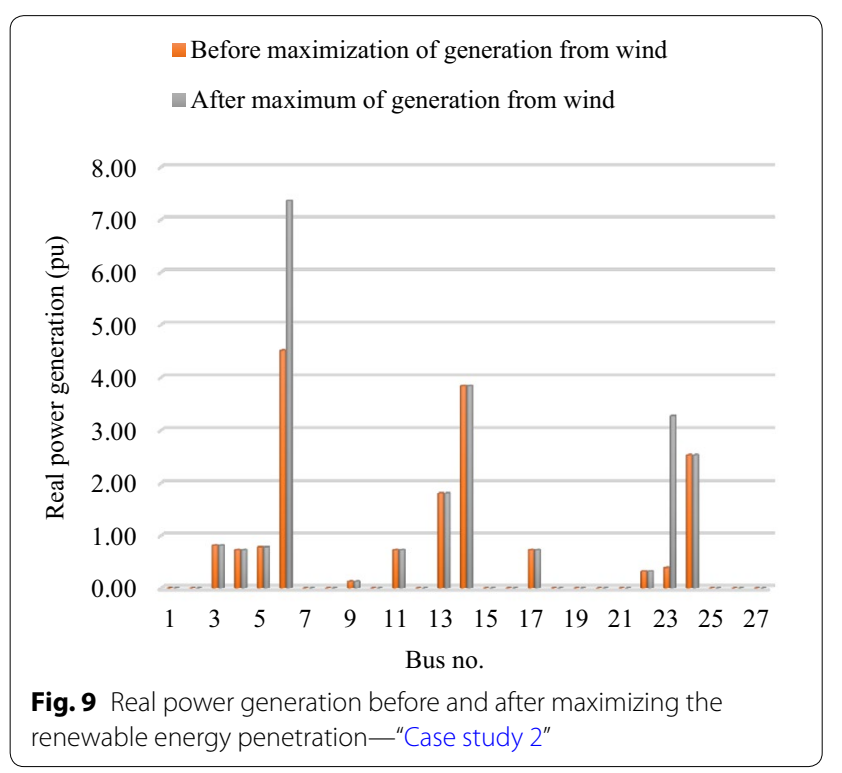

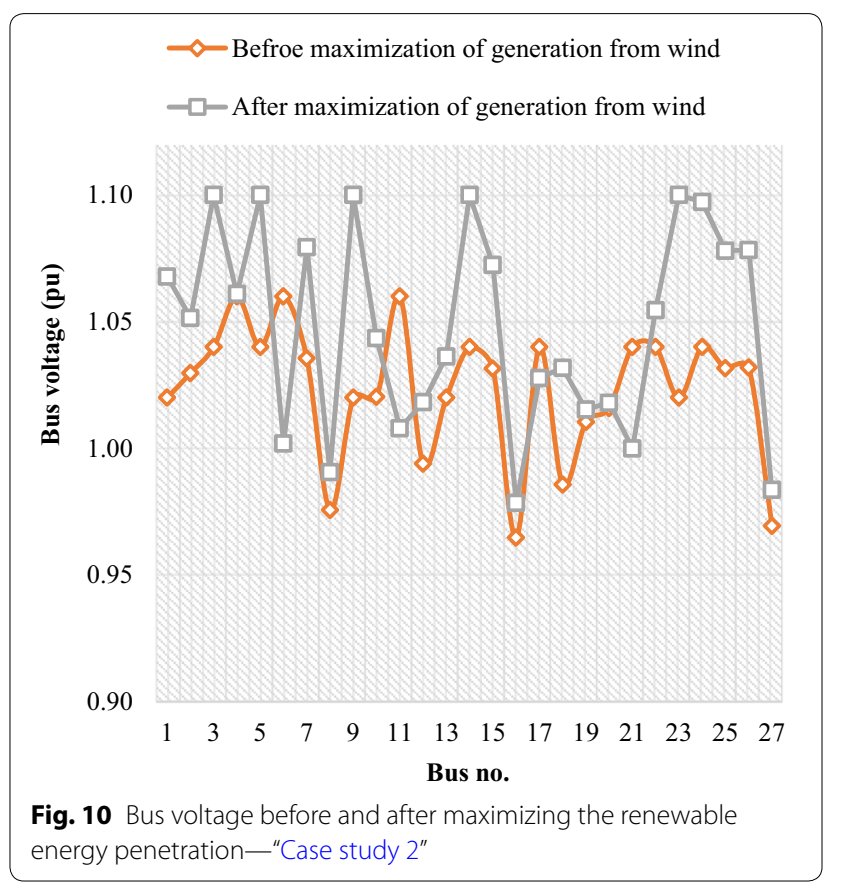




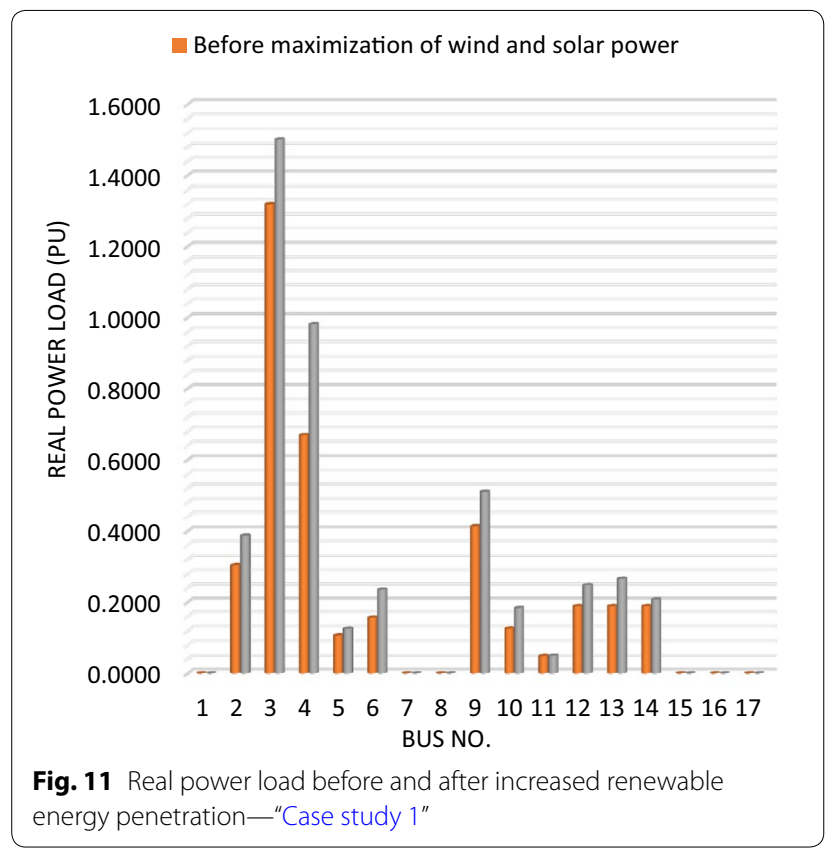

Dynamic higher-order model of the grid has been incorporated in the analysis. Moreover, the eigenvalue is computed for identifying the most influencing states that

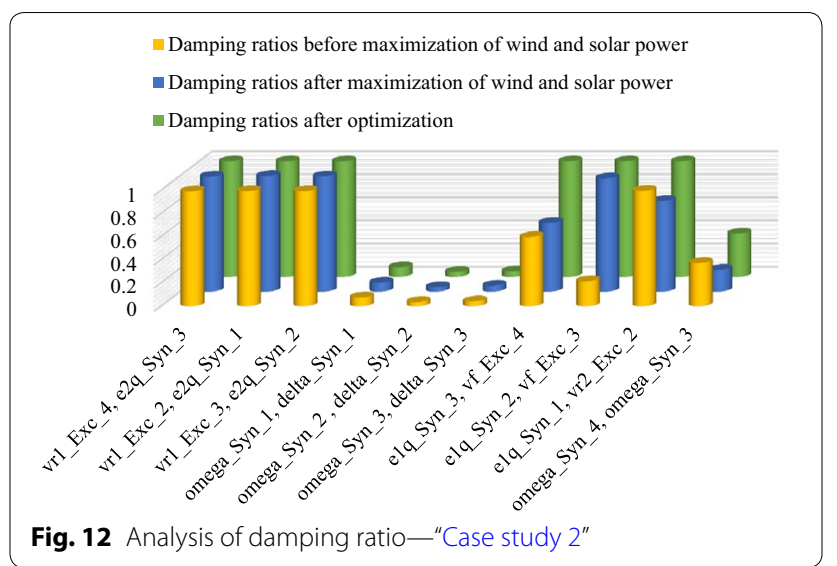

affects the maximum penetration of the wind and solar power in the power system. Also, the optimization is performed for improving the damping ratios and hence the small signal stability. This method is tested by using the IEEE 14-bus system and $220 \mathrm{kV}$ Indian grid. The total power generation from renewable resources has been increased to $392 \mathrm{MW}$ which was initially $143 \mathrm{MW}$ in the case of IEEE 14-bus system, and in the case of $220 \mathrm{kV}$ Kerala grid, the total power generation from the renewable resources has been increased to $473 \mathrm{MW}$ which was

Table 6 Comparison of damping ratios-Kerala grid with wind and solar power

\begin{tabular}{|c|c|c|c|c|c|c|}
\hline \multirow[t]{2}{*}{ Most associated states } & \multicolumn{2}{|c|}{$\begin{array}{l}\text { Before maximization of renewable } \\
\text { generation }\end{array}$} & \multicolumn{2}{|c|}{$\begin{array}{l}\text { After maximization of renewable } \\
\text { generation }\end{array}$} & \multicolumn{2}{|c|}{ After optimization of damping ratio } \\
\hline & Complex eigenvalue & Damping ratio & Complex eigenvalue & Damping ratio & Complex eigenvalue & Damping ratio \\
\hline vr1_Exc_4, e2q_Syn_3 & $-45.1074 \pm 4.6881 i$ & 0.995 & $-45.0517 \pm 4.7378 i$ & 0.995 & - & 1 \\
\hline vr1_Exc_2, e2q_Syn_1 & $-45.3261 \pm 2.7426 i$ & 0.998 & - & 1 & - & 1 \\
\hline vr1_Exc_3, e2q_Syn_2 & $-45.1933 \pm 3.5004 i$ & 0.997 & $-45.0827 \pm 3.6811 i$ & 0.997 & - & 1 \\
\hline $\begin{array}{l}\text { omega_Syn_1, delta_ } \\
\text { Syn_1 }\end{array}$ & $-0.5605 \pm 7.6214 i$ & 0.076 & $-0.5715 \pm 7.5274 i$ & 0.076 & $-0.6046 \pm 7.447 i$ & 0.082 \\
\hline $\begin{array}{l}\text { omega_Syn_2, delta_ } \\
\text { Syn_2 }\end{array}$ & $-0.3286 \pm 8.85 i$ & 0.0371 & $-0.41918 \pm 10.9843 i$ & 0.038 & $-0.4534 \pm 0.9322 i$ & 0.042 \\
\hline $\begin{array}{l}\text { omega_Syn_3, delta_ } \\
\text { Syn_3 }\end{array}$ & $-0.2935 \pm 7.0098 i$ & 0.0418 & $-0.35146 \pm 7.0287 i$ & 0.05 & $-0.3113 \pm 7.064 i$ & 0.047 \\
\hline e1q_Syn_3,vf_Exc_4 & $-3.0218 \pm 4.0428 i$ & 0.599 & $-3.0404 \pm 4.1021 i$ & 0.595 & - & 1 \\
\hline e1q_Syn_2,vf_Exc_3 & $-0.34682 \pm 1.5612 i$ & 0.217 & $-3.7871 \pm 0.77427 i$ & 0.98 & - & 1 \\
\hline e1q_Syn_1,vr2_Exc_2 & - & 1 & $-0.6291 \pm 0.49498 i$ & 0.786 & - & 1 \\
\hline $\begin{array}{l}\text { omega_Syn_4, omega_ } \\
\text { Syn_3 }\end{array}$ & $-0.6992 \pm 1.7335 i$ & 0.374 & $-0.39893 \pm 2.0688 i$ & 0.189 & $-0.689 \pm 1.7435 i$ & 0.375 \\
\hline
\end{tabular}


initially $185 \mathrm{MW}$. From the results, it is analyzed that the proposed multistage optimization technique increased the renewable energy penetration by satisfying all the grid requirements. Also, it efficiently optimized the small signal stability by tuning the control variables. The analysis concludes that the real control strategy required for the integrated operation can be obtained through offline optimization studies. Therefore, this work recommends the use of real-time coordination and control for the management of active and reactive power at all layers of the grid to address issues concerning the intermittency of renewable energy sources.

\begin{abstract}
Abbreviations
$\lambda_{f}$ : load factor; $\gamma$ : coefficient to adjust the slope of the function; $\lambda_{f}^{\max }$ : max. limit of load factor; $\mathrm{VL}$ : thermal and bus violation limit factor; OLL; overload line factor of line i; $\mathrm{BVV}_{\text {; }}$ bus voltage violation factor at bus j; $\mathrm{Nl}$ and $\mathrm{Nb}$ : total number of transmission lines and total number of buses in the system, respectively; $\tau_{\mathrm{BW}}$ and $\tau_{\mathrm{OLL}}$ : coefficients that used to adjust the slope of functions; $\zeta$ : damping ratio; $K_{\mathrm{a}}$ : exciter amplifier gain; $K_{f}$ exciter stabilizer gain; $R$ : turbine governor droop; $Z$ : line impedance; $V_{i}$ voltage at the sending end bus; $X$ : line reactance; $Q_{r}$ : reactive power at the receiving end of transmission line; $V_{s}$ : sending end voltage of transmission line; $\theta$ : line impedance angle; $\delta$ : angle difference between supply voltage and receiving voltage; $P_{i}$ : active power at the sending end bus; $P_{i}$ : active power at the receiving end bus; $Q_{i}$. reactive power at sending end bus; $Q_{j}$ : reactive power at the receiving end bus; $R_{w ;}$ : wind speed rank of bus $j ; C_{\mathrm{v}}$ : voltage constant; $R_{\mathrm{v} v}$ : voltage rank of bus $j ; C_{\mathrm{vs}}$ : voltage sensitivity index constant; $R_{\mathrm{VSI}}$ : voltage sensitivity index rank of bus j; $C_{i}$ : interconnection cable length constant; $R_{i j}$ : interconnection cable length rank of bus $j$; $I_{\text {gridi }}$ index of grid connection of bus j; $P_{b i}$ : local best particle; $G_{b i}$ : global best particle; $\omega$ : inertia weight function; $a_{1}$ and $a_{2}$ : acceleration constants.
\end{abstract}

\section{Authors' contributions}

TKR and SS conceived of the presented idea. TKR developed the theory and performed the computations. PR supervised the findings of this work. All authors discussed the results and contributed to the final manuscript. All authors read and approved the final manuscript.

\section{Author details}

${ }^{1}$ Department of Electrical and Electronics Engg., Govt. Engg. College, Thrissur, Kerala, India. ${ }^{2}$ Krishnathulasi, Karakkad, Kavalappara P O, Shoranur, Palakkad, Kerala 679523, India. ${ }^{3}$ Department of EEE, Govt. Engg. College, Thrissur, Kerala, India. ${ }^{4}$ Department of CSE, MES College of Engineering, Kuttippuram, Malappuram, Kerala, India.

\section{Competing interests}

The authors declare that they have no competing interests.

\section{Publisher's Note}

Springer Nature remains neutral with regard to jurisdictional claims in published maps and institutional affiliations.

Received: 12 February 2018 Accepted: 20 August 2018

Published online: 21 September 2018

\section{References}

Bessa, R., Moreira, C., Silva, B., \& Matos, M. (2014). Handling renewable energy variability and uncertainty in power systems operation. Wiley Interdisciplinary Reviews: Energy and Environment, 3, 156-178. https://doi. org/10.1002/wene.76.
Byrne, R. H., Concepcion, R. J. B., Neely, J., Wilches-Bernal, F., Elliott, R. T., Lavrova, O., et al. (2016). Small signal stability of the western North American power grid with high penetrations of renewable generation. In 2016 IEEE 43rd photovoltaic specialists conference (PVSC) (pp. 1784-1789).

Chatterjee, S., Abishek, N., \& Mukherjee, V. (2016). Small-signal stability analysis of DFIG based wind power system using teaching learning based optimization. International Journal of Electrical Power \& Energy Systems, 78(672-689), 2016.

Edrah, M., Kwok Lo, K. L., \& Anaya-Lara, O. (2015). Impacts of high penetration of DFIG wind turbines on rotor angle stability of power systems. IEEE Transactions on Sustainable Energy, 6(3), 759-766.

Eitigani, D., \& Masri, S. (2015). Challenges of integrating renewable energy sources to smart grids: A review. Renewable and Sustainable Energy Reviews, 52(770-780), 2015. https://doi.org/10.1016/j.rser.2015.07.140.

Erdinc, O., Paterakis, N. G., \& Catalavo, J. P. S. (2015). Overview of insular power systems under increasing penetration of renewable energy sources: Opportunities and challenges. Renewable and Sustainable Energy Reviews, $52,333-346$.

Khare, V., Nema, S., \& Baredar, P. (2016). Solar-wind hybrid renewable energy system: A review. Renewable and Sustainable Energy Reviews, 58, 23-33. https://doi.org/10.1016/j.rser.2015.12.223.

Krishan, R., Verma, A., \& Prasad, B. (2014). Small signal stability analysis of grid connected distributed PV and wind energy system. In 20146 th IEEE power India international conference (PIICON) (pp. 1-6).

Krismanto, A. U., Nadarajah, M., \& Krause, O. (2015). Influence of renewable energy based microgrid on low frequency oscillation of power systems. In 2015 IEEE PES Asia-Pacific power and energy engineering conference (APPEEC) (pp. 1-5). https://doi.org/10.1109/appeec.2015.7380982.

Kroposky, B., Johnson, B., Zhang, Y., Gevorgian, V., Denholm, P., Hodge, B., et al. (2017). Achieving a 100\% renewable grid: Operating electric power systems with extremely high levels of variable renewable energy. IEEE Power and Energy Magazine, 15(61-73), 2017. https://doi.org/10.1109/ mpe.2016.2637122.

Liu, W., Ge, R., Li, H., \& Ge, J. (2014). Impact of large-scale wind power integration on small signal stability based on stability region boundary. Sustainability, 6, 7921-7944. https://doi.org/10.3390/su6117921.

Liu, S., Liu, P. X., \& Wang, X. (2015). Stochastic small-signal stability analysis of grid-connected photovoltaic systems. IEEE Transactions on Industrial Electronics, 63, 1027-1038. https://doi.org/10.1109/TIE.2015.2481359.

Liu, S., Wang, X., \& Liu, P. X. (2017). A stochastic stability enhancement method of grid-connected distributed energy storage systems. IEEE Transactions on Smart Grid. https://doi.org/10.1109/TSG.2015.2514286.

Mehta, B., Bhatt, P., \& Pandy, V. (2014). Small signal stability analysis of power systems with DFIG based wind power penetration. International Journal of Electrical Power \& Energy Systems, 58(64-74), 2014. https://doi. org/10.1016/j.jiepes.2014.01.005.

Mehta, B., Bhatt, P., \& Pandey, V. (2015). Small signal stability enhancement of DFIG based wind power system using optimized controllers parameters. International Journal of Electrical Power \& Energy Systems, 70, 70-82.

Nikolic, D., Negnevitsky, M., \& Groot, M. (2015). Effect of the diesel engine delay on stability of isolated power systems with high levels of renewable energy penetration. In 2015 international symposium on smart electric distribution systems and technologies (EDST) (pp. 70-73).

Pandey, S. K., Mohanty, S. R., Kishor, N., \& Catalão, J. P. S. (2014). Frequency regulation in hybrid power systems using Particle Swarm Optimization and linear matrix inequalities based robust controller design. International Journal of Electrical Power \& Energy Systems, 63, 887-900.

Rahman, H. A., Majid, M. S., Jordehi, A. R., Gan, C. K., Hassan, M. Y., \& Fadhi, S. O. (2015). Operation and control strategies of integrated distributed energy resources: A review. Renewable and Sustainable Energy Reviews, 51, 1412-1420.

Ray, P. K., Paital, S. R., Mohanty, A., Panigrahi, T. K., Kumar, M., \& Dubey, H. (2016). Swarm and bacterial foraging based optimal power system stabilizer for stability improvement. In 2016 IEEE region 10 CONFERENCE (TENCON) (pp. 1916-1920). https://doi.org/10.1109/tencon.2016.7848355.

Sahu, A., Shrivatava, A., \& Khare, A. (2014). Particle Swarm Optimization based power system stabilizer to enhance power system small signal stability. International Journal of Electrical, Electronics and Computer Engineering., 3(1), 137-141. 
Sandhu, M., \& Thakur, T. (2014). Issues, challenges, causes, impacts and utilization of renewable energy sources-grid integration. International Journal of Engineering Research and Applications, 4, 636-643.

Sreedharan, S., Ongsakul, W., \& Singh, J. G. (2010). Maximization of wind penetration using Particle Swarm Optimization. International Journal of Engineering, Science and Technology, 2(5), 39-50.

Sreedharan, S., Ghorbani, R., Sepasi, S., Ongsakul, W., \& Singh, J. G. (2015). Simultaneous optimization of renewable power at transmission and distribution grid. Procedia Technology, 21(24-32), 2015.
Tang, Y., He, H., Wen, J., \& Liu, J. (2015). Power system stability control for a wind farm based on adaptive dynamic programming. IEEE Transactions on Smart Grid, 6(166-177), 2015. https://doi.org/10.1109/TSG.2014.2346740.

Wei, S., Zhou, Y., \& Huang, Y. (2017). Motor-generator pair: A novel solution to provide inertia and damping for power system with high penetration of renewable energy. IET Generation, Transmission and Distribution. https:// doi.org/10.1049/iet-gtd.2016.1894.

Yan, P., \& Sekar, A. (2002). Study of linear models in steady state load flow analysis of power systems. In IEEE power engineering society winter meeting.

\section{Submit your manuscript to a SpringerOpen ${ }^{\circ}$ journal and benefit from:}

- Convenient online submission

- Rigorous peer review

- Open access: articles freely available online

- High visibility within the field

- Retaining the copyright to your article

Submit your next manuscript at $\boldsymbol{\nabla}$ springeropen.com 